\title{
Executive Coaching Process: Flexibility in Leader's Decision-Making Process
}

Nasreen Nawab, Mohd Mursyid Arshad, Ismi Arif Ismail, Zoharah Omar

To Link this Article: http://dx.doi.org/10.6007/IJARBSS/v11-i19/11714

DOI:10.6007/IJARBSS/v11-i19/11714

Received: 04 October 2021, Revised: 01 November 2021, Accepted: 26 November 2021

Published Online: 21 December 2021

In-Text Citation: (Nawab et al., 2021)

To Cite this Article: Nawab, N., Arshad, M. M., Ismail, I. A., \& Omar, Z. (2021). Executive Coaching Process: Flexibility in Leader's Decision-Making Process. International Journal of Academic Research in Business and Social Sciences, 11(19), 14-25.

Copyright: (C) 2021 The Author(s)

Published by Human Resource Management Academic Research Society (www.hrmars.com)

This article is published under the Creative Commons Attribution (CC BY 4.0) license. Anyone may reproduce, distribute, translate and create derivative works of this article (for both commercial and non-commercial purposes), subject to full attribution to the original publication and authors. The full terms of this license may be seen

at: http://creativecommons.org/licences/by/4.0/legalcode

Special Issue Title: Youth and Community Wellness, 2021, Pg. 14 - 25

Full Terms \& Conditions of access and use can be found at http://hrmars.com/index.php/pages/detail/publication-ethics 


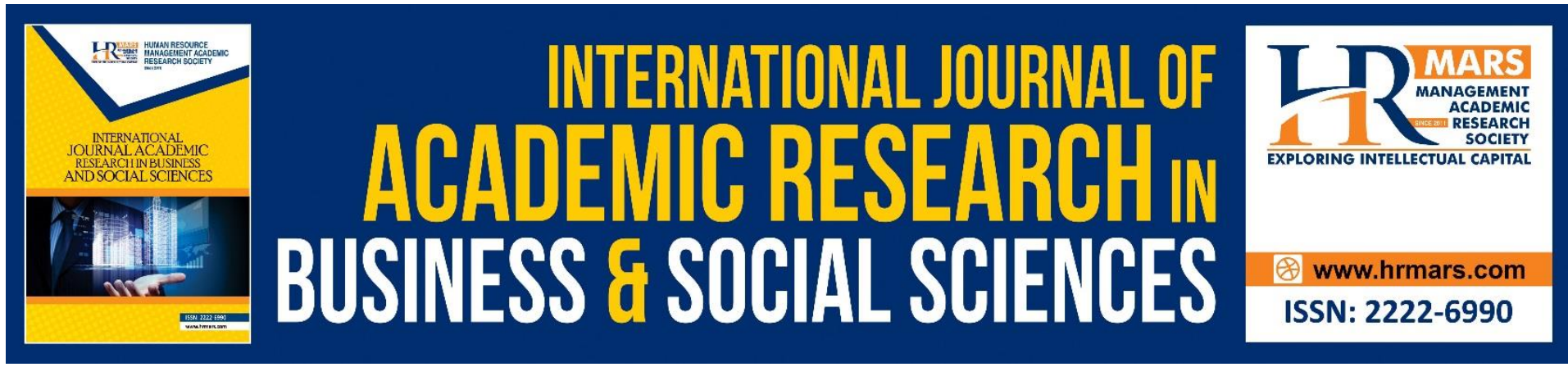

\title{
Executive Coaching Process: Flexibility in Leader's Decision-Making Process
}

\author{
Nasreen Nawab², Mohd Mursyid Arshad ${ }^{1,2}$, Ismi Arif Ismail ${ }^{1,2}$, \\ Zoharah Omar² \\ ${ }^{1}$ Institute for Social Science Studies, Putra Infoport, Universiti Putra Malaysia, 43400 UPM \\ Serdang, Selangor, Malaysia, ${ }^{2}$ Faculty of Educational Studies, Universiti Putra Malaysia, \\ 43400, Serdang, Selangor, Malaysia.
}

Corresponding Author:m_mursyid@upm.edu.my

\begin{abstract}
The overwhelmingly demanding world today demand for high quality leaders. Leaders should continually equip themselves with necessary skills to anticipate the changing environment which drive pressure for a more effective leadership development, especially in private organisations. In relation to this, coaching has emerged in the human resource development practice as a powerful development tool in improving leadership skills of executive leaders. The aim of this research is to look at the outcome of coaching in term of improving coachee's leadership competencies. From the findings, one of the changes is that it improves coachee's flexibility in their behaviours, mindset, and approaches in the decision-making process. This knowledge could be linked to the value that coaching to bring to coachee. Using a qualitative case study approach, data were collected through semi-structured in-depth interviews that involved eight informants from both coaches and coachees. Selection criteria for the coaches were individuals who have conducted executive coaching programmes extensively as part of their service for more than five years and have reached to the level of professionalism as Professional Certified Coach (PCC). The coachees were selected from individuals who hold executive position in their organisations that has participated in any executive coaching programmes in Malaysia. As a newly emerging tool, there are still a lot of scepticism around what are the real values of coaching and what are the positive changes that the process could bring in the area of leadership development. As such, this study could add to the body of knowledge, as well as deepen the understanding on learnings in coaching process which is translated into the outcome of coaching. Changes only occurs when learning occurs during the process.
\end{abstract}

Keywords: Executive Coaching, Coaching Process, Learning Process, Leadership Development.

\section{Introduction}

To date, more and more organizations are investing in putting together coaching programs in place. The goal of coaching is to improve a leader's effectiveness to ensure sustainability and organizational success (Cox et al., 2014; Maltbia et al., 2014). One aspect that coachee 
discovered from their participation in a mid to long-term coaching program is that it improves their flexibility in terms of mindset, behaviors, and their decision-making process (Densten \& Grey, 2001). It helps the coachee to operate in a more open paradigm, moving away from rigidity and fixed solutions which enhance the capacity and potential of coachee (Speltz, 2013).

Powerful questioning and critical reflection play a vital role in challenging conventional thinking to consider other viewpoints and allowing coachee to assess their situation deeper. Brookfield (1995) suggested that critical reflection is a deeper, more intense inquiry to assess current reality and making sense of the situation from various viewpoints along with limiting beliefs and biases. Boud et al., 1985 stated that the effectiveness of reflective practice is determined by how effective an individual can learn from their personal experience. Critical reflection facilitates formation of new knowledge and new behaviours by making meaning through experience (Rigg \& Trehan, 2008).

Ulrich (2008) highlighted that powerful questioning is helpful in promoting coachee to be involved in a reflection process. Powerful questioning challenges the status quo of coachee's belief and presumptions (Gloss, 2012; Hemphill; 2014; Barlow, 2005). This process helps to improve coachee's leadership development by encouraging coachee to be flexible in their approach allowing themselves to be detached from their personal assumption and belief, while examining different views and perspective (Densten \& Grey, 2001).

Rubin and Goldman (1968) highlighted that a leader must be able to be flexible enough to change accordingly to address to the situational needs. Ronen (1989) suggested that flexible leader could manage complexity and uncertainty, display adaptability, tolerate ambiguity, anticipate changes, display openness, empathy, and a willingness to acquire new behaviours and attitudes.

\section{Literature Review Executive Coaching}

Executive coaching has gained acceptance (Bozer, Sarros \& Santora, 2014) a major development method thanks to their complexities that combine many disciplines capable of addressing diverse needs in the evolving and competitive climate. The term Executive refers to representatives in the upper and highest levels of their organisations, including CEOs, Vice Presidents, Managers of plant or business units, and Managing Directors of organisations (Long, 2003). Coaching may be applied for various purposes, including development, performance, professional development and training programmes (Griffiths \& Campbell, 2016; Ingleton, 2013). While different types of coaching are implemented on the market, numerous commonalities can be found in different applications such as the common goaldirected and solution-focused framework (Griffiths \& Campbell 2016).

Three main skills of listening, questioning and contemplation have been used for productive and advanced coaching to create high impact, successful conversation and training (Starr, 2016; Ingleton, 2013). Strong questioning by coaches promotes the process of instilling inspiration and reflection in coaches. (Arnold, 2016; Leong, 2008). Coaching provides a healthy forum for thinking and room for more development and progress (Ingleton, 2013). The act of prompting questions to coachee is aimed at enabling coachees to evaluate their situation and to find solutions to their own problems (Arnold, 2016). The ability to use open ended questions is the key to develop a deeper understanding of a coachee's personal perception (Cox et al., 2015). 
In coaching, coaches assume that the answers and solutions to the issue lie inside the coachee. The method should be inward-looking and not outward-looking. Giving direct guidance rarely shifts people's views because of human nature, which pulls back when we were pushed back. (Leong, 2008). As such, the coaching process allows coaches to use and cultivate the expertise, experience and ability of coaches to reach optimum potential. (Arnold, 2016). Leong (2008) in his book clarified that the explanation behind the lack of a coaching approach is that coaches do not have full and complete knowledge to offer guidance and to suggest solutions to an issue. In the case of coaches able to provide full-length information, the method by which the information was examined could have gone through sequence and layers of interpretation before being transmitted to coaches. As such, it will include a high degree of bias that may make recommendations unrelated to the topics or problems being addressed. Gallwey, the coaching pioneer (2000), found out that the coach's job is to realise that all the information and solutions that were already available inside the coachee and to work with the information and potential that the coachee already has. Although coaching knowledge is in the coaching process and not particular content or organisation or industry, it is crucial for coaches to have a context in which to create trust and manage the complexity of the problem. (Brennan \& Hellborn, 2016). A coach should have unique skills and techniques to cultivate and inspire individual ability (Leong, 2008).

\section{GROW Model}

GROW model is closely linked to knowledge and accountability, which is an appropriate method for problem-solving and individual personal growth (Arnold, 2016). The uniqueness of the GROW model is that it is designed to prepare a course of transformation (Rostron, 2013). The first step is the coach and coachee needs to define the behaviours that they want to improve and set a target to achieve. Second, the coachee then required to carry out a reality check to recognise a reasonable starting point for achieving their goals. This is to offer clear expectations of the process. This reality check is activated by a coach asking questions like "what," "why," "where," "who," and "how much" (Zenger \& Stinnett, 2010; Arnold, 2016). The third step in GROW model is exploring the options. At this point, coaches encourage coachees to creatively come up with as many possible ways to start thinking more deeply about the problem being addressed. The final step is the evaluation of the choices and the determination of the will to make decisions (Zenger \& Stinnett, 2010). Lane and Corrie (2006) framed a three-pronged coaching model; Purpose, Perspectives, Process model. This model helps to organise the coaching process from identifying the problems and needs of coaches to sharing conclusions and viewpoints on the problems, and to map the steps and improvements required to achieve the result. These three measures are widely used in most coaching processes. The questions lead the coachee to convey the assumption and perceptions that they have never really shared before (Rostron, 2013).

\section{Decision-making through Executive Coaching}

Applying and incorporating the concepts of andragogy into the coaching process is a hidden ingredient in making coaching an efficient method but coaching as an adult is responsible for deciding their learning outcomes that are compatible with their level of knowledge and engagement in all aspects of coaching experience (Illeris, 2003). Toit (2014) described coaching in her findings as a psychological space that legitimises the space for coachees to return to their minds and think deeper. This "sacred spot" encourages deep thought and reflection which allows inner learning. The reflective space created by the coaching process 
includes the exploration of self-concept, including beliefs, emotions, principles, and morals within the sense-making and decision-making process, accompanied by mutual respect and trust (International Coaching Federation, 2017). Three key elements of adult learning that make a major contribution to the coaching process are self-directed, vital reflection and experiential (International Coaching Federation, 2017; Bougea, 2003, Brookfield, 2003). Coachings are a higher-level learning that involves certain skills in reasoning (Ladyshewsky, 2007) that include the ability to comprehend and engage in multidimensional communication (Leong, 2008). Leaders, to a certain degree, are often able to apply indirect learning from the coaching process and to associate it with various aspects of their job or personal life.

Costa and Garmston (2002) have defined mental states as an internal mechanism of thought to enhance and increase our potential and capacity. State of mind cannot be specifically examined, but its influence can be examined. Its principal driver is the growth attitude that contributes to, affects, motivates, and encourages intellectual capacity. Five provisions of the state of mind defined by Costa and Gramston (1994) promote successful thought and actions that have strengthened skills and capacities in relation to problem solving, reasoning and decision-making.

\section{Methodology}

\section{Qualitative Case Study}

This study adopts a qualitative case study research to understand outcome of executive coaching program in Malaysia. The case study focuses on in-depth interviews to capture holistic picture of the phenomenon, as suggested by Merriam \& Tisdell (2018) that a "case study is an empirical inquiry that investigates a contemporary phenomeon (the case) within its real-life context especially when the boundaries between phenomenon and context may not be clearly evident".

In this study, the qualitative approach explores a bounded system for one case based on indepth data collection involving multiple resources of information such as observations, interviews and document analysis. The study concentrates on executive coaching program conducted by coaches certified under the International Coaching Federation (ICF) with the intention to supplement the practise of coaching with deeper understanding on the impact of coaching.

\section{Sampling}

Data were collected through semi-structured in-depth interviews that involved 8 informants; 5 executives as coachee which participated in executive coaching program in their organisation and 3 certified coaches under International Coaching Federation (ICF). All informants included in this study are based in Kuala Lumpur, with 10 to 28 years of working experiences. Apart from that as for the coachee, all coachees selected for this research are holding senior management level in their respective organisation and have participated in any one to one executive coaching program. The duration of their past coaching experience must not exceed a year as to ensure coachee can still remember details of the coaching experience. This study deployed purposive sampling and snowball techniques.

Coachee participated in executive coaching programs carried out by coaches certified by ICF. All coaches were at the level of Professional Certified Coach (PCC) and have conducted executive coaching programmes extensively as part of their service for more than five years. 
Coachees were reached out to get their consent to participate in the study. The process of selecting the coachee is based on the snowballing technique as all the executives were the coachees of the selected coach. With the level of trust being built between the coach and coachee through the program, the level of acceptance was higher. Ultimately, selection of informants comprised of those who were able and willing to provide necessary information on the issues under study (Merriam \& Tisdell, 2016).

\section{In-depth Semi Structured Interview}

This qualitative investigation utilises in-depth interviews with open-ended and semistructured questions. The semi structured approach allows the informants to share their own perspective on a particular topic. "...less sturucted formats allow respondents to define the world in unique ways..." (Merriam \& Tisdell, 2018). The questions are focussed to understand the outcome of the coaching process.

The semi-structured approach encouraged information flow accompanied by probing questions that allowed informants to elaborate meaning from their own perspective. Structured questions were used to gather specific and important information required from informants to be able to interpret a situation better (Merriam, 2009), and to guide the researcher to gather information critical for this study (Merriam \& Tisdell, 2016).

\section{Findings and Discussion}

This research captured the impact of coaching based on informants' previous coaching experiences. It will provide insight into some areas of positive changes that coaching contributed in informants' developments, indirectly, apart from solving problem or issues that coachee brought to the table. One area of improvement that will be discussed deliberately in this paper is that leaders learn to adopt flexibility in their approach as an indirect influence from the coaching.

A coach encourages coachee to explore unlimited possibilities and options, without being confined to certain rigid structure or model. Informants highlighted that the flexibility they experienced throughout the coaching process inspired them to adopt similar approach at work. The flexibility fosters creative thinking and allow coachee to look at various perspective and alternatives in their decision-making process.

\section{How Leaders Trained to be more Flexible from the Process of Coaching?}

Informants described that they achieved flexibility from coaching through the following process:

(1) Applying and adopting various mindset.

(2) Being responsible to take action to change; and

(3) Being trained to have enquiring mind.

\section{Applying and Adopting Various Mindset}

The coach sincere enthusiasm ignites inspiration to engage in thought-provoking process where coachee are encouraged to seek various viewpoints and findings new insights (Canfield \& Chee, 2014). Coach always encourage coachee to constantly looking for new ways to solve a particular situation or issues. Coaches were not expecting perfect solutions and appreciate 
the journey of exploration to access a situation better.

"...Finding the options; and for each option, what are the good thing and bad things. And if I have tried options and I didn't get anything, that is when she comes in and say, have you check any other options that you can try out. The questions help me to think in a structured manner..."

Asking the right questions stimulate coachee to have wider perspective and facilitate sequential flow of thinking that allow deeper exploration to connect the missing link. Starr (2016) explains that questions push coachee's mind towards certain direction to immediately find answers. Without providing specific direction, coachee starts to gain confidence to express their thoughts and continue drawing wisdom within them from their life experiences.

"...The solution is from me... and before this I doubt that...but because of the questions, so I knew I can do this... the self-confident, it makes me confident about myself that I can do this, and I can think about all this. I have all the solution, I have the knowledge, just need to...you know...prob myself...that's good..."

Whenever coachee verbalised their thoughts, they could think and see things more clearly. Feasibility or practicality of the solution were not questioned during the thought process. The process is to gather valuable insights on the endless possibilities before jumping into premature conclusions. Asking the right questions at the right time, will lead the through process into various angle.

"...learning opportunity is very much triggered through the questions and the questions could be clarifying questions, it could be challenging questions, it could be provoking questions, it could be questions that get them deep into thinking, why are they thinking that, why is it affecting them like that..."

\section{Be Responsible to Take Action to Change}

Coaching encourages self-leadership where coachee are empowered to be willing to lead themselves to be better, taking initiatives and being proactive. The empowerment developed sense of ownership within coachee in taking charges of their own development with the help of a coach. However, a coaching session is not session to download and share their problem to a coach, but it requires coachee to agree on action plan to move forward.

"...in the simulation process, you are already draw learnings from your past but the drawing of learning from the past as a clear intention of execution in the future..."

Coachee's transformational journey begins when they begin to take action and make progress towards realizing their objectives.

"...because then the conversation will focus on what you need to do to achieve it? Because talking about how bad the situation does is, doesn't change it, it's only talking about what you are going to do about it, will change it..."

Talking about problem and identifying solutions is the starting point to move towards taking 
action but the real learnings happens when coachee challenged themselves and stretch themselves out of their comfort level and create room to grow.

"...If they can accept the stand, the wonderful thing is that they will do something about it... Do you want to change? Or is there something else that you want to do about it... what you want to do about it? This is the first thing about their learning..."

When coachee reaches to higher level of flexibility in their approach, they begin to accept differences within people and value the opinion of others. It teaches coachee to look into actions that is within their control yet having high consideration of others. Coach 2 highlighted:

"...in term of learning that they shift the focus and instead of blaming the person ... they take responsibility, they have way more positive approach..."

Apart from the unwavering attention given by the coach, coaching assignments or action plan present a new challenge to be completed after each session. This could guide coachee to move to the right direction of their transformational journey. Realisation from the coaching conversations is translated into action plan where the learnings is taking place "...Every single coaching section ends with an action plan, so it is directly transferred...".

Coachee should not be push into taking action that coachee feels not workable. Changes did not happen in one day and the learnings from a coaching process will be embedded within coachee that could change the way coachee approach similar things in the future "...Well, the outcome, can be that they have better understanding and next time they can take action differently..."

Being a leader, coachee is overwhelmed with so many things to manage that requires their attention at the same time. Coaching space offers a space where coachee could filter the unnecessary noise in their mind. Coaching space provide a moment for coachee to reflect and to think deeper.

"...sometimes we are thinking too much about certain thing and because of work and other things, it clouded us to take a step back. So, she tried to help us align what we think. So, we need to find out what are the best solutions because no one else could tell me how to do it, these are best solutions for me. I need to think what's best for me..."

Coaching process prepares coachee to be independent in their thinking process. A coach facilitates coachee to structure their thinking pattern and going into the right direction. Coachee felt self-empowered when they chart own action plan to solve their issues. This encourages flexibility in their thinking knowing there are hidden learning opportunity yet to be discovered at any time.

\section{Being Trained to have Enquiring Mind}

Coaching conversation create a learning platform for coachee to realise untapped potential and becoming a reality check for them. Without being asked or being questioned, we will never realise about things that we don't know. 
"...So, by asking what you want instead, what is your best hope, what is your preferred future that you want, you will be able to unearth, a lot of the challenges..."

Coachee are being trained to have enquiring mind to explore solutions and options every time they are faced with any challenge. Asking the right questions will help to dig the root of the issues which open up new learning potential for coachee to build new competency on area that they are lacking. Without being questioned, there are no discovery on the root cause of a particular issue and realisation on areas that coachee need to develop.

"...Questions that challenge them, clarify, questions that make them want to move forward, these is the questions, questions that go deep into their heart..."

Questions were designed to help coachee to think deeper and realise the potential future that they would like to achieve. Questions are personalised according to the flow of the conversation without a rigid structure to follow. Personalisation is a key strength of a coaching process. Questions help to align coachee with their thinking and discover things that are important to them.

"...Like I said just now, I always told him in detail what's happening, what is the complaint and why did I do that, my reason, and he would go by asking me questions, same time giving me options, he didn't give me answers, that is where I need to think, to say, how to I react..."

Although coachee shared their action, thoughts and insight with a coach in a coaching process, the action plan and solution still need to come from themselves and not from the coach (Casserley \& Critchley, 2010; Starr, 2006). This process is to give them sense of perspective and structure their thought process.

\section{Conclusions}

Coachee acknowledged that the process instilled flexibility in their approach facilitate open mind and ready for endless possibilities which not limiting thems to a certain expectation as they led their own learning and realisation. This flexibility fosters creative thinking and allows coachee to look at various perspective and alternatives before coming up to a final decision in their decision-making process.

Given the huge responsibility and busy schedule, leaders spend very minimal time reflecting and thinking which usually put the opportunity to learn from experience and feedback to waste. The coaching space facilitate coachee in real business times (Bougea, 2005) which able to provide support to a leader in processing issues and challenges that face at work from various perspective (Starr, 2016; Ulrich; 2008; Witherspoon \& White, 1996) before making decision. This helps to improve flexibility in leaders via having wider perspectives and increases their agility.

Learning within coaching is about process. The process develops thinking skill within leaders that change their behaviors which made them a better leader. The process of applying and adopting various mindset; being held responsible to take action to change; and being trained to have enquiring mind improves leaders' flexibility in making suitable decision based on the situational needs of the organization. Longenecker and McCartney (2020) the real-time 
support empowered leaders to make timely decision which are critical in order to adapt to the changing nature of current business landscape.

One drawback for this study is that it requires long-term commitment to the data collection process. This relates to the essence of the coaching process where the coaching relationship must be built on trust and confidence before the coachee feels secure to discuss any concerns or problems. In an attempt to acquire comprehensive knowledge from the coachee, it is best to assess the process over a period of time once confidence, relationship and chemistry have been established (Bozer et al., 2014).

For future studies on leadership development through executive coaching process could explore deeper on the mechanism of learnings and its pathways towards leadership development. This knowledge is required to build understanding on how to utilise internal capabilities in order to drive actions and behaviour in coachee. Understanding the framework provide a structure as mechanism to connect the behaviours and actions with their existing belief and perspectives to optimise the transformational journey.

\section{References}

Anderson, D., \& Anderson, M. (2016). Coaching That Counts. Taylor \& Francis Group. Arnold, J. (2016). Coaching Skills for Leaders in the Workplace. London. UK: Robinson.

Barlow, L. (2005). Effective structuring of coaching: using five questions. Development and Learning in Organizations. An International Journal, 11-12.

Boud, D., Keogh R. \& Walker D. (1985). Promoting reflection in learning: a model. Kogan page, London, 38-40.

Bougae, C. (2005). A descriptive study of the impact of executive coaching from the perspective of the executive leader. Capella University.

Brennan, D., \& Hellbom, K. (2016). Positive team coaching. Industrial and Commercial Training, 333-337.

Brookfield, S. D. (2003). A critical theory perspective on accelerated learning. San Francisco: Jossey-Bass.

Bozer, G., Sarros, J. C., \& Santora, J. C. (2014). Executive Coaching: Guidelines that work. Development and Learning in Organizations. An International Journal, 28(4), 9-12.

Brookfield, S. D. (1995). Becoming a Critically Reflective Teacher. San Francisco: Jossey-Bass.

Casserley, T. \& Critchley, B. A New Paradigm of Leadership Development. Industrial and Commercial Training, 287.

Costa, A. L., \& Garmston, R. J. (1994). Cognitive Coaching: A Foundation for Renaissance Schools. Massachusetts: Christopher - Gordon Publishers Inc

Costa, A. L., \& Garmston, R. J. (2002). Cognitive Coaching: A Foundation for Renaissance Schools. Massachusetts: Christopher - Gordon Publishers Inc.

Cox, E. (2014). Theoretical Traditions and Coaching Genres: Mapping the Territory. Advances in Developing Human Resources.

Cranfield, J., \& Chee, P. (2014). Coaching for Breakthrough Success: Proven Techniques for Making Impossible Dreams Possible. McGraw-Hill Education. United States.

Densten, I. L., \& Gray, J. H. (2001). Leadership Development and Reflection: What is the connection? International Journal of Educational Management, 119-124.

Gallwey, T. W. (2000). The Inner Game of Work. Orion Business Books. London

Gloss, E. J. (2012). A Hint of This and A Pinch of That: Theories That Inform Coaching and 
Consulting. Graduate Studies Journal of Organizational Dynamics, 2. University of Pennsylvania.

Griffiths, K., \& Campbell, M. (2009). Discovering, Applying and Integrating: The Process of Learning in Coaching. International Journal of Evidence Based Coaching and Mentoring, 16-30

Hemphill, D. C. (2014). Coaching From the Coaches' Perspective: A Process-Oriented Focus. International Journal of Mentoring And Coaching In Education, 72-85.

Illeris, K. (2003). Workplace Learning and Learning Theory. Journal of Workplace Learning, 167-178.

Ingleton, C. (2013). The Miracle of Coaching. Industrial And Commercial Training, 289- 292.

International Coaching Federation (2017). Retrieved From Www.Coachfederation.Org.

Jones, R. A., Rafferty, A. E., \& Griffin, M. A. (2006). The Executive Coaching Trend: Towards More Flexible Executive. Leadership \& Organization Development Journal, 27 (7), 584596.

Lane, D. A., \& Corrie, S. (2006). The Modern Scientist - Practitioner: A Guide to Practise in Psychology. Routledge. London.

Leong, W. K. (2008). Empowering Asian Mindsets Through Coaching: Discover the Secrets of Empowerment Using The Nine Coaching Mindsets. Malaysia, Pelanduk Publications (M) Sdn Bhd.

Longenecker, C. O., \& McCartney, M. (2020). The Benefits of Executive Coaching: Voices from the C-Suite. Strategic HR Review.

Maltbia, T. E., Marsick, V. J., Ghosh, R. (2014). Executive and Organizational Coaching: A Review of Insights Drawn from Literature to Inform HRD Practice. Advances In Developing Human Resources, 16(2), 161-183.

Meriam, S. B. (1998). Qualitative Research and Case Study Application In Education. San Francisco, Cs: Jossey-Bass Publishers.

Meriam, S. B. (2009). Qualitative Research as Qualitative Research. Qualitative Research in Higher Education. Boston, Ma: Pearson Custom Publishing. 191-200

Merriam, S. B., \& Tisdel, E. J. (2016). Qualitative Research: A Guide to Design and Implementation. San Francisco: Jossey-Bass.

Meriam, S. B. (1998). Qualitative Research and Case Study Application In Education. San Francisco, Cs: Jossey-Bass Publishers.

Meriam, S. B. (2009). Qualitative Research as Qualitative Research. Qualitative Research in Higher Education. Boston, Ma: Pearson Custom Publishing. 191-200

Merriam, S. B., \& Tisdel, E. J. (2016). Qualitative Research: A Guide to Design and Implementation. San Francisco: Jossey-Bass.

Rekalde, I., Landeta, J., \& Albizu, E. (2015). Determining Factors in The Effectiveness of Executive Coaching as A Management Development Tool. Management Decision, 53(8), 1677-1697.

Rigg, C \& Trehan, K (2008). Critical Reflection in The Workplace: Is It Just Too Difficult?". Journal of European Industrial Training, 32(5), 374 - 384.

Ronen, S. (1989), "Training the International Assignee", In Goldstein, I. (Ed.) Training \& Development in Organisations, Jossey-Bass, San Francisco, Ca.

Rostron, S. (2013). What Progress Has Been Made In Coaching Research In Relation To 16 ICF Focus Areas From 2008 To 2012? Coaching. An International Journal of Theory, Research and Practice, 6(1).

Rubin, I. M., And Goldman, M. (1968). An Open System Model of Leadership Performance. 
Organizational Behavior and Human Performance, 3, 143-56.

Speltz, M. E. (2013). Defining Critical Factors in Executive Coaching Relationships from The Perspective of The Executive Coaching. Minneapolis. University of Minnesota.

Starr, J. (2016). The Coaching Manual. United Kingdom. Pearson Education Limited.

Toit, A. D. (2014). Making Sense of Coaching. Great Britain Sage.

Ulrich, D. (2008). Executive Coaching Hones Competitive Edge. Credit Union Executive Newsletter, 26(32), 2-4.

Witherspoon, R., \& Randall, P. W. (1996). Executive Coaching: What's in It for You. Training \& Development, 50(3).

Zenger, J. H., \& Stinnett, K. (2010). The Extraordinary Coach: How the Best Leaders Help Others Grow. United States of America: McGraw-Hill. 